\title{
VEGF Polymorphisms Are Associated With Endocardial Cushion Defects: A Family-Based Case-Control Study
}

\author{
HUBERDINA P.M. SMEDTS, AARON ISAACS, DOMINIQUE DE COSTA, ANDRÉ G. UITTERLINDEN, CORNELIA M. VAN DUIJN, \\ ADRIANA C. GITTENBERGER-DE GROOT, WILLEM A. HELBING, ERIC A.P. STEEGERS, \\ AND RÉGINE P.M. STEEGERS-THEUNISSEN \\ Departments of Obstetrics and Gynecology [H.P.M.S., D.D.C., E.A.P.S., R.P.M.S.-T.], Epidemiology [A.I., C.M.D., R.P.M.S.-T.], Internal \\ Medicine [A.G.U.], and Clinical Genetics [R.S.], University Medical Center, Rotterdam 3015 GD, The Netherlands; Department of \\ Pediatrics [W.A.H., R.P.M.S.-T.], Sophia Children's Hospital, Rotterdam 3015 GD, The Netherlands; Department of Anatomy and \\ Embryology [A.C.G.G.], Leiden University Medical Center, Leiden 2300 RC, The Netherlands
}

\begin{abstract}
Endocardial cushion defects (ECDs) of the cardiac outflow tract are among the most common congenital heart disease phenotypes. VEGF is essential for endocardial cushion formation and derangements in VEGF synthesis lead to ECD. Three functional single nucleotide polymorphisms (SNPs) in the VEGF gene -2578 $\mathrm{C}>\mathrm{A},-1154 \mathrm{G}>\mathrm{A}$, and $-634 \mathrm{G}>\mathrm{C}$ play a role in cardiogenesis. In a Dutch case-control family study of triads, 190 case and 317 control children with both parents, we investigated linkage and association between these VEGF SNPs and ECD. Allele frequencies for the three $V E G F$ SNPs were comparable between ECD children and controls. However, VEGF alleles $-2578 \mathrm{C}$ and $-1154 \mathrm{G}$ were transmitted more frequently to children with $\operatorname{ECD}(p=0.003$ and $p=0.002)$, in particular perimembranous ventricular septal defects $(p=0.012$ and $p=0.006)$. The $-2578 \mathrm{~A} /-1154 \mathrm{~A} /-634 \mathrm{G}$ haplotype was associated with a reduced risk of ECD (OR $0.7 ; 95 \%$ CI, 0.6-1.0) and was significantly less transmitted to children with $\operatorname{ECD}(p=0.002)$. In a Dutch population, we show that the VEGF $2578 \mathrm{C},-1154 \mathrm{G}$ alleles, and the AAG haplotype are associated with ECD. Possible VEGF gene-environment interactions exposures are discussed. (Pediatr Res 67: 23-28, 2010)
\end{abstract}

$\mathrm{C}$ ongenital heart diseases are the most frequent major congenital malformations with a worldwide birth prevalence rate of over one million per year (1). Because of the high infant mortality and morbidity rates, the causes of these malformations should be identified and targeted for preventive strategies in the future (2). Most congenital heart diseases have a complex origin, in which interactions between subtle genetic variations and periconception exposures play a role (3). Vasculogenesis and heart development are dependent on the genetic constitution of the embryo derived from both parents, and the maternal genetically controlled nutritional, endocrine and metabolic environment (4). During cardiac development, the outflow tract is divided into the ascending aorta and the pulmonary trunk and aligned to the left and right ventricle, respectively. The formation of the endocardial cushions in the atrioventricular canal and outflow tract takes place by epithe-

Received June 3, 2009; accepted September 10, 2009.

Correspondence: Régine P.M. Steegers-Theunissen, M.D., Ph.D., Department of Obstetrics and Gynecology, Erasmus MC, University Medical Center, Dr. Molewaterplein 40, 3015 GD Rotterdam, The Netherlands; e-mail: r.steegers@erasmusmc.nl

Supported by the Corporate Development International (grant 2005) and Netherlands Heart Foundation (grant 2002.B027). lial-mesenchymal transformation, which is a key process in the development of the heart septa and valves. Numerous lines of research have implicated a strict spatiotemporal expression pattern of the VEGF gene in the control of endocardial cushion development (5). In addition to its tight regulation during cardiogenesis, $V E G F$ gene expression is also regulated by environmental exposures. A nice example is that hypoxia induces $V E G F$ gene expression and seems to contribute as such to the generation of major malformations in the atrioventricular-canal and outflow tract in mice (6). Hyperglycemia inhibits epithelial-mesenchymal transformation by reducing $V E G F$ gene expression (7). Furthermore, hyperhomocysteinemia, which increases the risk of human congenital heart disease, was shown to up-regulate VEGF mRNA in a human endothelial cell line (8). Interestingly, vegf120/120 mutant mouse embryos, showing overexpression of the VEGF120isoform and lacking the other VEGF-isoforms, develop endocardial cushion defects (ECDs), such as ventricular septal defects, pulmonary valve stenosis (PS), and Tetralogy of Fallot (TOF) $(9,10)$.

In human, the VEGF gene is located on chromosome 6 p21.3 and consists of eight exons that generate different isoforms through alternative splicing. $V E G F$ gene expression shows a marked individual variability, which is partly determined by single nucleotide polymorphisms (SNPs). The most interesting functional SNPs that differentially express VEGF in vitro are $V E G F-2578 \mathrm{C}>\mathrm{A}$ and $-1154 \mathrm{G}>\mathrm{A}$, located in the promoter (11), and $V E G F-634 \mathrm{G}>\mathrm{C}$, located in the 5 'untranslated region of the gene (12). Initially, studies suggest associations between the VEGF SNPs $-2578 \mathrm{C}>\mathrm{A}$, $-1154 \mathrm{G}>\mathrm{A}$, and $-634 \mathrm{G}>\mathrm{C}$ and several congenital heart disease phenotypes (13-15).

In a large Dutch case-control family study of triads, i.e. child, mother, father, we investigated whether three functional SNPs in the VEGF gene, i.e. $-2578 \mathrm{C}>\mathrm{A},-1154 \mathrm{G}>\mathrm{A}$, and $-634 \mathrm{G}>\mathrm{C}$, affect the risk of ECD, being the most common subgroup of congenital heart disease phenotypes.

Abbreviations: ECD, endocardial cushion defect; FBAT, family-based association test; HBAT, haplotype-based association test; PS, pulmonary valve stenosis; pVSD, perimembranous ventricular septal defect; SNP, single nucleotide polymorphism; TOF, Tetralogy of Fallot 


\section{MATERIALS AND METHODS}

Study design and population. This study was embedded in the Dutch Haven study, which is an ongoing case-control family study of triads in the western part of the Netherlands, initated to investigate the etiology and future prevention of congenital heart disease in which genetic and environmental factors are implicated. Details of the study design and population were described previously (16). Briefly, the domain population comprised case and control children, between 12 and 18 mo of age, living in the western part of the Netherlands. Children with a congenital heart disease were diagnosed by two pediatric cardiologists from the Erasmus MC, University Medical Center in Rotterdam, Leiden University Medical Center in Leiden, VU University Medical Center, and Amsterdam Medical Center in Amsterdam, in the Netherlands. In collaboration with the pediatric cardiologists, the case children with their parents were enrolled. In the Haven study, we included case families of which the index child had a congenital heart defect in which gene-environment interactions are implicated in the etiology (17-19). VEGF is reported to play a role in endocardial cushion formation. Therefore, in the current analysis of associations between SNPs in the VEGF gene and congenital heart defects we selected from the total case group of the Haven study, only the ECD phenotypes, i.e. perimembranous ventricular septal defect (pVSD), PS, TOF, aortic valve stenosis (AoS), and atrioventricular septal defect (AVSD). Figure 1 depicts the flow chart of the study population. Between October 2003 and January 2007, we ascertained 289 children with congenital heart disease and 317 control children with their parents. In the current analysis, only Dutch native children and children from other European origin were included to increase ethnic homogeneity. Children were classified as Dutch natives when both parents and grandparents are born in the Netherlands or one of the parents is born in another country, but both grandparents are born in the Netherlands. If one of the parents or grandparents is born in a European country or is from European origin and living in the United States, Australia, or Indonesia, we classified the child in the category European Others (20). Non-European children and families with Mendelian inconsistencies or unsuccessful genotyping for all three SNPs were also excluded. In total, SNP data from 190 case-children with ECD and both parents and 317 control-children with both parents were available for the analyses. All phenotypes were ascertained by ultrasound and/or cardiac catheterization and/or surgery and diagnosed according to the International Pediatric and Congenital Cardiac Code (21). The ECD group consisted of 122 children with isolated and 68 with complex ECD. Complex ECD was defined as ECD with the co-occurrence of any other structural congenital anomaly. The group of complex ECD was further subdivided into 46 children of which the ECD was part of a syndrome: Trisomy $21(n=34)$, deletion 22q13 $(n=1)$, deletion 22q11 $(n=2)$, insertion $1>3(n=1)$, Noonan syndrome $(n=1)$, CHARGE syndrome $(n=1)$, Duane syndrome $(n=1)$, Turner syndrome $(n=2)$,

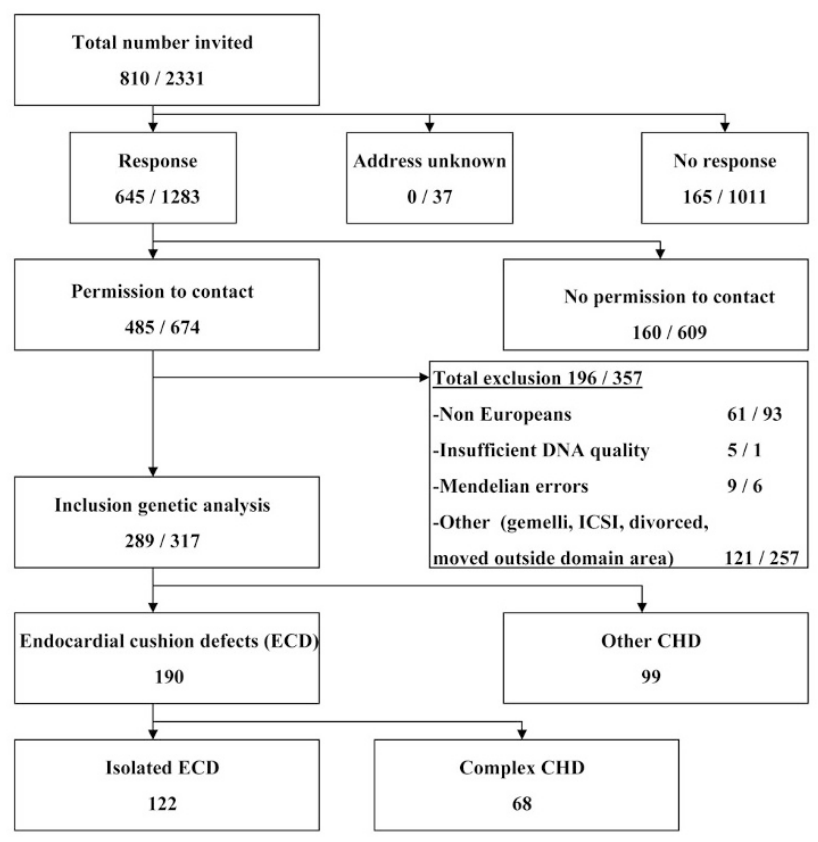

Figure 1. Study population flowchart. Numbers are the absolute numbers of case mothers/control mothers. $\mathrm{CDH}$, congenital heart disease.
VACTRL ( $n=1)$, Alagille syndrome $(n=1)$ and Beckwith Wiedemann syndrome $(n=1)$, and 22 children with ECD and other anomalies that could not be traced to a syndrome, such as hydronefrosis, hip dysplasia, hypospadia, cleft lip and/or palate, pyloric stenosis, clubfoot, and deafness. Control children and their parents were enrolled in collaboration with public child health centers in the Rotterdam area. The Dutch health care system includes a standardized and regular check up of all newborns for health, growth, and development by physicians trained in child health care. Children were eligible as controls if they did not have a major congenital malformation or chromosomal defect according to the medical records from the regular check up at the child health center. Both cases and controls were invited to participate at a fixed study moment at 16 mo of age of the child. At that time, the diagnosis of congenital heart diseases is confirmed. All children originated from the western part of the Netherlands. None of the families was related, all were familiar with the Dutch language in speaking and reading, and none of the children has been adopted. Potential participating parents were informed about the genetic research questions of the Haven study. Only children of whom the parents confirmed to be both the biologic parent participated. All mothers completed a general questionnaire from which we extracted for the current analyses demographic data, child's gender, family history of congenital heart disease, and ethnicity. The study protocol was approved by the Central Committee of Research in Humans in The Hague, the Netherlands, 2003, and the local Medical Ethical Committees of the four participating hospitals, 2003. Written informed consent was obtained from all parents, on behalf of their child as legal representatives.

Genotyping. DNA was isolated from EDTA blood with a Total Nucleic Acid Extraction kit on a MagNAPure LC (Roche Molecular Biochemicals, Mannheim, Germany). DNA was isolated from buccal swabs from four case-children, one case-father, and one control-father, due to logistical problems or failures in blood sampling. Genotypes were determined in 1-2 ng of genomic DNA with TaqMan allelic discrimination assays and analyzed using the software SDS 2.2.2 (Applied Biosystems, Foster City, CA). Case and control triads were genotyped for $V E G F$ SNPs at positions $-2578 \mathrm{C}>\mathrm{A}$, $-1154 \mathrm{G}>\mathrm{A}$, and $-634 \mathrm{G}>\mathrm{C}$, numbered from the translation start site. Primers and probes of $-2578 \mathrm{C}>\mathrm{A}$ (rs699947), -1154 G>A (rs1570360), and $-634 \mathrm{G}>\mathrm{C}$ (rs2010963) were obtained from Applied Biosystems (http://www.appliedbiosystems.com). Each genotype plate contained no DNA template (water) controls. To check consistency, we randomly chose $5 \%$ of samples and repeated the measurements. Reproducibility was $100 \%$.

Statistical analysis. General characteristics were compared between children with ECD and controls. The comparisons between dichotomous variables, presented as numbers and percentages, were tested by $\chi^{2}$ tests. Frequencies of $V E G F$ alleles and genotypes were calculated for children with ECD and controls, and haplotype frequencies were estimated using UNPHASED 3.0 (22). $D^{\prime}$ and $r^{2}$ values of linkage disequilibrium (LD) between SNPs were estimated using Haploview 3.3.2 (23). Deviations from Hardy-Weinberg equilibrium (HWE) were tested using $\chi^{2}$ tests with one degree of freedom. $\chi^{2}$ tests were also used to evaluate differences in the distributions of alleles, genotypes, and haplotypes between case and control children and separately for each ECD phenotype. A

Table 1. General characteristics of the case-children with ECD and control-children

\begin{tabular}{lcc}
\hline & ECD & Controls \\
\hline Child & $n=190$ & $n=317$ \\
Age at the study moment & $16.2(15.1-19.2)$ & $16.1(15.1-18.0)$ \\
$\quad$ in months, median & & \\
$\quad$ (interquartile range) & & \\
Boys, $n(\%)$ & $96(51)$ & $170(54)$ \\
Family history for & $18(10)$ & $17(5)$ \\
CHD*, $n(\%)$ & & \\
Ethnicity $\dagger, n(\%)$ & $177(93)$ & $289(91)$ \\
Dutch natives & $13(7)$ & $28(9)$ \\
European Others &
\end{tabular}

* Any congenital heart disease of family members in the first, second, or third degree.

$\dagger$ Children were classified as Dutch natives when both parents and grandparents are born in the Netherlands or one of the parents is born in another country, but both grandparents are born in the Netherlands. If one of the parents or grandparents is born in a European country, or is from European origin and living in the United States, Australia, or Indonesia, we classified the child in the category European Others.

$\mathrm{CHD}$, congenital heart disease. 
Table 2. Distribution of the VEGF genotypes in case-children with ECD and control-children

\begin{tabular}{|c|c|c|c|c|c|}
\hline $\begin{array}{l}V E G F \\
\text { SNPs }\end{array}$ & $\begin{array}{c}\text { ECD } \\
n=185\end{array}$ & $\begin{array}{l}\text { Controls } \\
n=312\end{array}$ & $\chi^{2}$ & Fisher's $p$ & OR $(95 \% \mathrm{CI})$ \\
\hline \multicolumn{6}{|l|}{-2578} \\
\hline AA & $44(24)$ & $88(28)$ & 2.52 & 0.28 & $0.8(0.6-1.1)$ \\
\hline $\mathrm{CA}$ & $88(48)$ & $153(49)$ & & & $0.8(0.5-1.2)$ \\
\hline $\mathrm{CC}$ & $53(29)$ & $71(23)$ & & & 1.0 (reference) \\
\hline $\begin{array}{l}\text { HWE } \\
\quad p \text { value }\end{array}$ & - & 0.77 & & & \\
\hline \multirow[t]{2}{*}{ C-allele } & $194(52)$ & $295(47)$ & 2.38 & 0.12 & \\
\hline & $n=187$ & $n=307$ & & & \\
\hline \multicolumn{6}{|l|}{-1154} \\
\hline AA & $18(10)$ & 43 (14) & 2.32 & 0.31 & $0.8(0.6-1.1)$ \\
\hline GA & $79(42)$ & $130(42)$ & & & $0.9(0.6-1.3)$ \\
\hline GG & $90(48)$ & $134(44)$ & & & 1.0 (reference) \\
\hline $\begin{array}{l}\text { HWE } \\
\qquad p \text { value }\end{array}$ & - & 0.20 & & & \\
\hline \multirow[t]{2}{*}{ G-allele } & $259(69)$ & $398(65)$ & 1.55 & 0.21 & \\
\hline & $n=184$ & $n=303$ & & & \\
\hline \multicolumn{6}{|l|}{-634} \\
\hline $\mathrm{CC}$ & $22(12)$ & 39 (13) & 0.26 & 0.88 & $1.0(0.7-1.3)$ \\
\hline $\mathrm{GC}$ & $85(46)$ & $133(44)$ & & & $1.1(0.7-1.6)$ \\
\hline GG & 77 (42) & $131(43)$ & & & 1.0 (reference) \\
\hline $\begin{array}{l}\text { HWE } \\
\quad p \text { value }\end{array}$ & - & 0.57 & & & \\
\hline G-allele & $239(65)$ & $395(65)$ & 0.00 & 1.00 & \\
\hline
\end{tabular}

Values are expressed as $n(\%)$.

ECD, outflow tract defect. logistic regression model was used to estimate the risk of the pooled group of ECD phenotypes. OR and 95\% CI were calculated. Statistical analysis was performed using SPSS software (version 12.0 SPSS Inc., Chicago, IL). We applied the family-based association test (FBAT), a transmission disequilibrium test (TDT)-like test statistic, to investigate linkage and association for $V E G F$ alleles (FBAT) and haplotypes (haplotype-based association test [HBAT]) (http://www.biostat.harvard.edu/ fbat/fbat.htm) (24). FBAT analyses were performed under an additive model. The 1-POET test, which is an extension of the TDT statistic, was used to detect a possible parent-of-origin effect (25). All tests were two-tailed and $p$ values were Bonferroni adjusted to account for multiple tests.

\section{RESULTS}

The general characteristics of children with ECD and controls are presented in Table 1. The distributions of age, gender, ethnicity, and family history of congenital heart disease were comparable between the children with ECD and controls.

Moderate linkage disequilibrium was shown between $V E G F$ $-2578 \mathrm{C}>\mathrm{A}$ and $-1154 \mathrm{G}>\mathrm{A}\left(r^{2}=0.52\right)$; between $V E G F$ $-2578 \mathrm{C}>\mathrm{A}$ and $-634 \mathrm{G}>\mathrm{C}\left(r^{2}=0.49\right)$; and between $V E G F-1154 \mathrm{G}>\mathrm{A}$ and $-634 \mathrm{G}>\mathrm{C}\left(r^{2}=0.26\right)$. The distributions of the $\mathrm{VEGF}$ alleles and genotypes are presented in Table 2. None of the genotype frequencies in the control population deviated from HWE. The genotype distributions of $V E G F-2578 \mathrm{C}>\mathrm{A},-1154 \mathrm{G}>\mathrm{A}$, and -634 $\mathrm{G}>\mathrm{C}$ were not significantly different between the children with ECD and controls. The VEGF $-2578 \mathrm{C}$ and $-1154 \mathrm{G}$ alleles were more frequently present, albeit not signifi-

Table 3. Distribution of the VEGF genotypes in case-children with ECD, stratified for ECD phenotypes, and control-children

\begin{tabular}{|c|c|c|c|c|c|c|}
\hline \multirow[b]{2}{*}{$V E G F$ SNPs } & \multicolumn{5}{|c|}{ ECD } & \multirow[b]{2}{*}{$\begin{array}{l}\text { Controls } \\
n=312\end{array}$} \\
\hline & $\begin{array}{c}\mathrm{pVSD} \\
n=79\end{array}$ & $\begin{array}{c}\text { PS } \\
n=42\end{array}$ & $\begin{array}{c}\text { TOF } \\
n=29\end{array}$ & $\begin{array}{l}\text { AVSD } \\
n=29\end{array}$ & $\begin{array}{c}\text { AoS } \\
n=6\end{array}$ & \\
\hline \multicolumn{7}{|l|}{-2578} \\
\hline $\mathrm{AA}$ & $15(19)$ & $12(29)$ & $6(21)$ & $9(31)$ & $2(33)$ & $88(28)$ \\
\hline $\mathrm{CA}$ & $44(56)$ & $14(33)$ & $16(55)$ & $11(38)$ & $3(50)$ & $153(49)$ \\
\hline $\mathrm{CC}$ & $20(25)$ & $16(38)$ & $7(24)$ & $9(31)$ & $1(17)$ & $71(23)$ \\
\hline$\chi^{2} ; p$ value* & 0.25 & 0.07 & 0.68 & 0.47 & 0.93 & \\
\hline HWE $p$ value & - & - & - & - & - & 0.77 \\
\hline C-allele & $84(53)$ & $46(55)$ & $30(52)$ & $29(50)$ & $5(42)$ & $295(47)$ \\
\hline \multirow[t]{2}{*}{$\chi^{2} ; p$ value $\dagger$} & 0.16 & 0.18 & 0.49 & 0.65 & 0.72 & \\
\hline & $n=79$ & $n=43$ & $n=29$ & $n=30$ & $n=6$ & $n=307$ \\
\hline \multicolumn{7}{|l|}{-1154} \\
\hline $\mathrm{AA}$ & $6(8)$ & $6(14)$ & $2(7)$ & $3(10)$ & $1(17)$ & $43(14)$ \\
\hline GA & $36(46)$ & $13(30)$ & $11(38)$ & $15(50)$ & $4(67)$ & $130(42)$ \\
\hline GG & $37(47)$ & $24(56)$ & $16(55)$ & $12(40)$ & $1(17)$ & $134(44)$ \\
\hline$\chi^{2} ; p$ value* & 0.31 & 0.27 & 0.39 & 0.68 & 0.40 & \\
\hline HWE $p$ value & - & - & - & - & - & 0.20 \\
\hline G-allele & $110(70)$ & $61(71)$ & $43(74)$ & $39(65)$ & $6(50)$ & $398(65)$ \\
\hline \multirow[t]{2}{*}{$\chi^{2} ; p$ value $\dagger$} & 0.24 & 0.28 & 0.16 & 1.00 & 0.36 & \\
\hline & $n=79$ & $n=43$ & $n=29$ & $n=27$ & $n=6$ & $n=303$ \\
\hline \multicolumn{7}{|l|}{-634} \\
\hline $\mathrm{CC}$ & $9(11)$ & $6(14)$ & $2(7)$ & $4(15)$ & $1(17)$ & $39(13)$ \\
\hline GC & $43(54)$ & $16(37)$ & $14(48)$ & $10(37)$ & $2(33)$ & $133(44)$ \\
\hline GG & $27(34)$ & $21(49)$ & $13(45)$ & $13(48)$ & $3(50)$ & $131(43)$ \\
\hline$\chi^{2} ; p$ value* & 0.24 & 0.71 & 0.64 & 0.79 & 0.87 & \\
\hline HWE $p$ value & - & - & - & - & - & 0.57 \\
\hline G-allele & $97(61)$ & $58(67)$ & $40(69)$ & $36(67)$ & $8(67)$ & $395(65)$ \\
\hline$\chi^{2} ; p$ value $\dagger$ & 0.35 & 0.75 & 0.54 & 0.81 & 1.00 & \\
\hline
\end{tabular}

Values are expressed as $n(\%)$, tested between case-children with ECD and controls by $\chi^{2}$.

* Comparison of genotypes between cases and controls.

$\dagger$ Comparison of alleles between cases and controls.

ECD, outflow tract defect. 
Table 4. Distribution of VEGF haplotypes in case-children with ECD and control-children

\begin{tabular}{|c|c|c|c|c|c|}
\hline $\begin{array}{c}V E G F \\
\text { haplotypes }\end{array}$ & & & & Fisher's & \\
\hline$-2578 /-1154 /-634$ & ECD & Controls & $\chi^{2}$ & $p$ & OR $(95 \% \mathrm{CI})$ \\
\hline AAG & $114.4(30)$ & $225.1(36)$ & 3.92 & 0.05 & $0.76(0.58-1.00)$ \\
\hline CGC & $133.4(35)$ & $220.2(35)$ & 0 & 1 & - \\
\hline CGG & $65.0(17)$ & $82.4(13)$ & 3.07 & 0.08 & $1.37(0.96-1.95)$ \\
\hline AGG & $65.1(17)$ & $104.8(17)$ & 0 & 1 & - \\
\hline
\end{tabular}

Values are expressed as $n(\%)$.

ECD, outflow tract defects.

Table 5. Family-based association analysis of VEGF alleles transmitted from heterozygous parents to case-children with the separate ECD phenotype

\begin{tabular}{|c|c|c|c|c|c|c|}
\hline & \multirow[b]{2}{*}{$\begin{array}{l}\text { Allele } \\
V E G F\end{array}$} & \multirow[b]{2}{*}{ Frequency } & \multicolumn{2}{|c|}{ FBAT } & \multicolumn{2}{|c|}{ FBAT-o } \\
\hline & & & $\begin{array}{l}\text { Informative } \\
\text { trios }\end{array}$ & $P$ & $\begin{array}{c}\text { Informative } \\
\text { trios }\end{array}$ & $p$ \\
\hline \multirow[t]{3}{*}{ ECD } & $-2578 \mathrm{C}$ & 0.490 & 136 & 0.015 & 366 & $0.003^{*}$ \\
\hline & $-1154 \mathrm{G}$ & 0.663 & 131 & 0.017 & 331 & $0.002 *$ \\
\hline & $-634 \mathrm{G}$ & 0.648 & 132 & 0.125 & 345 & 0.066 \\
\hline \multirow[t]{3}{*}{ pVSD } & $-2578 \mathrm{C}$ & 0.490 & 64 & 0.052 & 294 & 0.012 \\
\hline & $-1154 \mathrm{G}$ & 0.664 & 59 & 0.039 & 259 & 0.006 \\
\hline & $-634 \mathrm{G}$ & 0.639 & 63 & 0.185 & 276 & 0.099 \\
\hline \multirow[t]{3}{*}{ PS } & $-2578 \mathrm{C}$ & 0.494 & 32 & 0.170 & 262 & 0.060 \\
\hline & $-1154 \mathrm{G}$ & 0.668 & 32 & 0.217 & 232 & 0.063 \\
\hline & $-634 \mathrm{G}$ & 0.647 & 28 & 0.398 & 241 & 0.256 \\
\hline \multirow[t]{3}{*}{ TOF } & $-2578 \mathrm{C}$ & 0.489 & 18 & 0.239 & 248 & 0.109 \\
\hline & $-1154 \mathrm{G}$ & 0.670 & 19 & 0.221 & 219 & 0.084 \\
\hline & $-634 \mathrm{G}$ & 0.646 & 19 & 0.127 & 232 & 0.081 \\
\hline \multirow[t]{3}{*}{ AVSD } & $-2578 \mathrm{C}$ & 0.490 & 19 & 0.564 & 249 & 0.300 \\
\hline & $-1154 \mathrm{G}$ & 0.663 & 18 & 0.835 & 218 & 0.456 \\
\hline & $-634 \mathrm{G}$ & 0.642 & 19 & 0.852 & 232 & 0.892 \\
\hline AoS & NT & & & & & \\
\hline
\end{tabular}

FBAT-o incorporates information from control trios.

$* p$ values surviving Bonferroni correction for $5 \times 3$ independent tests, with $\alpha=0.0033$.

NT, sample size is too low; ECD, outflow tract defect. cantly, in children with ECD than in controls. The distribution of the genotypes stratified per ECD phenotype is summarized in Table 3. In children with PS, the distributions of the $-2578 \mathrm{C}>\mathrm{A}$ variants deviated from HWE, and in these children, the $\mathrm{C}$-allele tended to be more frequently present than in controls $(p=0.07)$. We inferred haplotypes from the three $V E G F$ polymorphisms and compared the frequencies. Four of the eight possible haplotypes occurred at an appreciable frequency in both children with ECD and controls, i.e. AAG, CGC, CGG, and AGG whereby each letter refers to the allele of the $-2578,-1154$, and -634 SNP, respectively (Table 4). Consistent with the genotype distributions, the haplotype analyses revealed that the CGG haplotype was present in $17 \%$ of children with ECD and in $13 \%$ of control children $(p=0.08)$. The AAG haplotype was associated with a reduced risk of the ECD phenotype (OR, 0.8; 95\% CI, 0.6-1.0).

The results of the FBAT analyses are depicted in Table 5 and point out that the $-2578 \mathrm{C}$ and $-1154 \mathrm{G}$ alleles were transmitted to children with an ECD more frequently than expected by Mendelian inheritance (59\% of all transmissions). FBAT-o, which also incorporates information from the control triads, revealed even stronger evidence for over transmission of the $-2578 \mathrm{C}$ allele $(p=0.003)$ and the $-1154 \mathrm{G}$ allele ( $p=0.002)$ to offspring with the ECD phenotype. These $p$ values survived the rather conservative Bonferroni correction for multiple testing of $5 \times 3$ independent test with $\alpha=$ 0.0033. Stratification for five separate ECD phenotypes revealed that the $-2578 \mathrm{C}$ allele $(p=0.012)$ and the $-1154 \mathrm{G}$ allele $(p=0.006)$ were significantly overtransmitted to children with pVSD. Consistently, the HBAT-o results suggested that the CGC haplotype was overtransmitted to children with $\operatorname{ECD}(p=0.057)$, and the AAG haplotype was significantly

Table 6. Family-based association analysis of VEGF haplotypes transmitted from parents to case-children with the separate ECD phenotype

\begin{tabular}{|c|c|c|c|c|c|c|c|}
\hline & \multirow[b]{2}{*}{$\begin{array}{c}V E G F \text { haplotypes } \\
-2578 /-1154 /-634\end{array}$} & \multirow[b]{2}{*}{ Frequency } & \multicolumn{2}{|c|}{ HBAT } & \multicolumn{2}{|c|}{ HBAT-o } & \multirow[b]{2}{*}{$\begin{array}{c}\text { HBAT }-\mathrm{p} \\
p\end{array}$} \\
\hline & & & $\begin{array}{c}\text { Informative } \\
\text { trios }\end{array}$ & $p$ & $\begin{array}{c}\text { Informative } \\
\text { trios }\end{array}$ & $p$ & \\
\hline \multirow[t]{4}{*}{$\mathrm{ECD}$} & CGC & 0.344 & 113.9 & 0.063 & 294.8 & .057 & 0.064 \\
\hline & AAG & 0.330 & 109.9 & 0.008 & 288.8 & $0.002 *$ & 0.007 \\
\hline & AGG & 0.173 & 76.0 & 0.612 & 202.9 & 0.492 & 0.611 \\
\hline & CGG & 0.148 & 78.0 & 0.538 & 184.0 & 0.299 & 0.489 \\
\hline \multirow{4}{*}{ pVSD } & CGC & 0.354 & 56 & 0.056 & 239 & 0.045 & 0.060 \\
\hline & AAG & 0.327 & 55 & 0.028 & 231 & 0.006 & 0.022 \\
\hline & AGG & 0.172 & 41 & 0.764 & 169 & 0.629 & 0.699 \\
\hline & CGG & 0.142 & 35 & 0.873 & 144 & 0.573 & 0.828 \\
\hline \multirow[t]{4}{*}{ PS } & $\mathrm{CGC}$ & 0.352 & 20 & 0.117 & 191 & 0.090 & 0.098 \\
\hline & AAG & 0.322 & 26 & 0.366 & 192 & 0.129 & 0.400 \\
\hline & AGG & 0.174 & 15 & 0.819 & 142 & 0.946 & 0.743 \\
\hline & CGG & 0.151 & 20 & 0.853 & 129 & 0.840 & 0.741 \\
\hline \multirow[t]{4}{*}{ TOF } & CGC & 0.350 & 18 & 0.276 & 189 & 0.220 & 0.371 \\
\hline & AAG & 0.320 & 15 & 0.221 & 181 & 0.090 & 0.322 \\
\hline & AGG & 0.180 & 13 & 0.816 & 140 & 0.944 & 0.717 \\
\hline & CGG & 0.149 & 14 & 0.590 & 123 & 0.435 & 0.462 \\
\hline \multirow[t]{4}{*}{ AVSD } & $\mathrm{CGC}$ & 0.359 & 13 & 0.513 & 184 & 0.650 & 0.614 \\
\hline & AAG & 0.326 & 12 & 0.405 & 178 & 0.227 & 0.449 \\
\hline & AGG & 0.174 & 10 & 0.808 & 137 & 0.709 & 0.654 \\
\hline & CGG & 0.140 & 11 & 0.166 & 120 & 0.113 & 0.205 \\
\hline AoS & NT & - & - & - & - & - & - \\
\hline
\end{tabular}

HBAT-o incorporates information from control trios.

$p$ value surviving Bonferroni correction for $5 \times 4$ independent tests, with $\alpha=0.0025$.

HBAT-p, 10,000 permutations; NT, sample size is too low; ECD, outflow tract defect. 
less frequently transmitted than expected to children with ECD (41\% of transmissions, which was significant at an Bonferroni $\alpha$-level of 0.0025) (Table 6), in particular to children with $\mathrm{pVSD}(p=0.022)$. Empirical $p$ values obtained by permutation analyses (HBAT-p) substantiated these associations. The global $p$ value with four degrees of freedom for differences in the transmission of the four haplotypes to children with ECD was $p=0.03$. We did not find any evidence for a parent-of-origin effect of risk alleles in the $V E G F$ candidate loci (data not shown).

\section{DISCUSSION}

This study provides evidence for an association between the $V E G F$ gene, in particular, the $V E G F-2578 \mathrm{C}$ and $-1154 \mathrm{G}$ alleles and AAG haplotype, and ECD in human.

Recently, Vannay et al. (14) demonstrated a higher frequency of the VEGF $-634 \mathrm{C}$ allele in Hungarian children with congenital heart disease. They included several congenital heart disease phenotypes with valvular and/or septal defects, which may explain the different results. In a Chinese study, the $V E G F-634 \mathrm{C}$ allele was shown to reduce the risk of a child with the pVSD phenotype (15). Our sample size of 79 children with pVSD and 317 controls was too limited to detect the association with this phenotype (power of $41 \%$, OR 0.7 , risk allele frequency $35 \%$, type I error of 0.05 , congenital heart disease population risk of 0.008). Lambrechts et al. (13) reported an increased risk of the VEGF -2578/-1154/-634 AAG haplotype for both nonsyndromic and DiGeorge syndrome-related TOF. However, we show that the same AAG haplotype was associated with a reduced risk for in particularly ECD. In our study, the VEGF $-2578 \mathrm{~A}$ and $-1154 \mathrm{~A}$ alleles were less frequent in children with TOF, although not significantly different from controls. The genetic differences that may exist between our Dutch population and their mixed population of Caucasians, Afro-Americans, Hispanics, and subjects from unknown origin might explain the differences in results. Furthermore, it cannot be excluded that selective survival is confounding their results as no information was provided on the age of the children with congenital heart disease at the moment of investigation. Moreover, maternal exposures in early pregnancy that seem to influence VEGF expression might also have led to the different results.

The effect of the studied VEGF SNPs on the expression in human, particularly the $V E G F$ isoforms, is not fully understood. In vegf $120 / 120$ mouse embryos, lacking the 164 and 188 isoforms, a spatiotemporal increase of VEGF coincides with hyperplasia of the outflow tract cushions and abnormally high levels of apoptosis. This manifests in later stages than TOF, pulmonary stenosis, and ventricular septal defects (10). In humans, higher VEGF production was observed in cells from individuals with the $-2578 \mathrm{C}$ and $-1154 \mathrm{G}$ alleles compared with $-2578 \mathrm{~A}$ and $-1154 \mathrm{~A}$ individuals in stimulated peripheral blood mononuclear cells from healthy volunteers (26). Individuals homozygous for the haplotypes containing the $-1154 \mathrm{AA}$ and -2578 AA genotypes also showed lower circulating VEGF than heterozygous individuals, whereas the VEGF AAG haplotype resulted in lower plasma
VEGF concentrations (27). We speculate that the AAG haplotype is associated with a reduced risk for ECD by modifying the spatiotemporal $V E G F$ expression during heart development.

Our findings suggest that the polymorphic promoter region of the VEGF gene, in particular the $-2578 \mathrm{C}$ and $-1154 \mathrm{G}$ alleles, contribute to a genetic predisposition to ECD. The genetic variants might cause a spatiotemporal increase in VEGF expression during endocardial cushion formation, superimposed on the developmental regulated program of expression. Hypoxia, hyperglycaemia, and hyperhomocysteinemia are suggested to modify VEGF expression during cardiogenesis $(5,6,8)$. The interaction between VEGF and homocysteine is of particular interest because both epidemiologic and experimental studies showed that maternal hyperhomocysteinemia increases the risk of offspring with in particular ECD (16-18). Folate shortage results in hyperhomocysteinemia and both folic acid and homocysteine affect the behavior of neural crest cells that are implicated in endocardial cushion formation (28). Periconception use of folic acid supplements was shown to reduce the risk of in particular neural crest-related congenital heart disease (19). VEGF functions as an endothelial-cell specific growth factor and affects epithelial, mesenchymal, and neural cells. It is unknown whether VEGF also influences neural crest cells. However, in future studies with large sample sizes these interactions should be further studied.

Some limitations and strengths of the study have to be addressed. Our dataset consisted of a relatively large set of ECD; however, sample sizes of the individual ECD phenotypes were relatively small, especially that of AoS. Therefore, with an a priori hypothesis and to minimize type I errors possibly occurring when testing the individual phenotypes, at first we pooled the five ECD phenotypes as they share similarities in pathogenetic background. However, as there may be differential effects between the phenotypes, we also presented the FBAT and HBAT results per ECD phenotype. We acknowledge the selection of only surviving children of $16 \mathrm{mo}$ of age with and without a congenital heart defect that may have resulted in an over- or underestimation of the risk estimates. Only a few data have been published on the mortality rates of congenital heart defects in the first year of life. To provide some estimation of the impact on the risk estimates, we calculated that the overall mortality rate of ECD in our hospital over the previous years was on average $2 \%$. The European Association of Cardio-Thoracic Surgeons (EACTS) reported mortality rates varying between $0.76 \%$ for AoS and $6.98 \%$ for complete AVSDs (29). The overall infant mortality rate in the first year of life in the developed world is $0.8 \%$. Therefore, it is not very likely that the selection of only surviving case and control children had a great impact on the conclusions of this study. The strength of our study is the detailed description of the ECD phenotypes and the ethnic homogeneity of case and control families. Moreover, the $V E G F$ genotypes are reliable as the distributions in the controls are largely comparable with healthy control subjects in other European study populations (27). Bonferroni correction is rather conservative when considering SNPs in linkage disequilibrium and may increase the risk of false negative results. However, to minimize the risk for type I errors, 
Bonferroni adjusted probability values were calculated for $5 \times 3$ and $5 \times 4$ independent tests for alleles and haplotypes, respectively. It is of note that the associations between the $V E G F-2578 \mathrm{C}(p=0.003)$ and $-1154 \mathrm{G}(p=0.002)$ allele as well as the AAG haplotype $(p=0.002)$ with ECD, as revealed from the FBAT-o and HBAT-o analyses, were of such magnitude that they would remain significant even after Bonferroni correction. The FBAT looks for distortions in the transmission frequencies of a given allele, compared with the assumption of random transmission. A TDT-like design, such as FBAT, is an attractive method because it is robust against population admixture or stratification (30). Another advantage of FBAT over standard TDT is the FBAT-o option, which also incorporates information on the control triads.

The observed associations between the VEGF polymorphisms at position -2578 and -1154 , the AAG haplotype, and ECD phenotypes require replication in an independent study group. The rapid expansion of knowledge regarding genetic profiling will in future lead to a more detailed characterization of congenital heart disease. Large studies addressing interactions between $V E G F$ and periconception environmental exposures as well as those investigating the signaling pathway upstream and downstream of $V E G F$ during cardiac cushion formation should be encouraged to modify ECD risk in future.

Acknowledgments. We thank all participating children and their parents. We thank Professor J. Ottenkamp and Dr. F.M.H. Siebel for their contributions in the recruitment of the case and control families. We are also indebted to Dr. A.C. Verkleij-Hagoort, Ms. L.M.J.W. van Driel, and Ms. S. Borst for data collection, to Mr. B. van Zelst and Mr. P. Arp for technical support, and to Dr. M. Wildhagen for his contribution to data management.

\section{REFERENCES}

1. March of Dimes Birth Defects Foundation 2006 Global Report on Birth Defects. The Hidden Toll of Dying and Disabled Children. March of Dimes Birth Defects Foundation, White Plains, New York, p 28

2. Yoon PW, Olney RS, Khoury MJ, Chavez GF, Taylor D 1997 Contribution of birth defects and genetic diseases to pediatric hospitalizations. A population-based study. Arch Pediatr Adolesc Med 151:1096-1103

3. Botto LD, Correa A 2003 Decreasing the burden of congenital heart anomalies: an epidemiologic evaluation of risk factors and survival. Prog Pediatr Cardiol 18:111121

4. Steegers-Theunissen RP, Steegers EA 2003 Nutrient-gene interactions in early pregnancy: a vascular hypothesis. Eur J Obstet Gynecol Reprod Biol 106:115-117

5. Armstrong EJ, Bischoff J 2004 Heart valve development: endothelial cell signalling and differentiation. Circ Res 95:459-470

6. Dor Y, Camenisch TD, Itin A, Fishman GI, McDonald JA, Carmeliet P, Keshet E 2001 A novel role for VEGF in endocardial cushion formation and its potential contribution to congenital heart defects. Development 128:1531-1538

7. Enciso JM, Gratzinger D, Camenisch TD, Canosa S, Pinter E, Madri JA 2003 Elevated glucose inhibits VEGF-A-mediated endocardial cushion formation: modulation by PECAM-1 and MMP-2. J Cell Biol 160:605-615
8. Roybal CN, Yang S, Sun CW, Hurtado D, Vander Jagt DL, Townes TM, Abcouwer SF 2004 Homocysteine increases the expression of vascular endothelial growth factor by a mechanism involving endoplasmic reticulum stress and transcription factor ATF4. J Biol Chem 279:14844-14852

9. Van den Akker NM, Molin DG, Peters PP, Maas S, Wisse LJ, van Brempt R, van Munsteren CJ, Bartelings MM, Poelmann RE, Carmeliet P, Gittenberger-de Groot AC 2007 Tetralogy of Fallot and alterations in vascular endothelial growth factor-A signaling and notch signaling in mouse embryos solely expressing the VEGF120 isoform. Circ Res 100:842-849

10. Van den Akker NM, Caolo V, Wisse LJ, Peters PP, Poelmann RE, Carmeliet P, Molin DG, Gittenberger-de Groot AC 2008 Developmental coronary maturation is disturbed by aberrant cardiac vascular endothelial growth factor expression and Notch signalling. Cardiovasc Res 78:366-375

11. Brogan IJ, Khan N, Isaac K, Hutchinson JA, Pravica V, Hutchinson IV 1999 Novel polymorphisms in the promoter and 5' UTR regions of the human vascular endothelial growth factor gene. Hum Immunol 60:1245-1249

12. Watson CJ, Webb NJ, Bottomley MJ, Brenchley PE 2000 Identification of polymorphisms within the vascular endothelial growth factor (VEGF) gene: correlation with variation in VEGF protein production. Cytokine 12:1232-1235

13. Lambrechts D, Devriendt K, Driscoll DA, Goldmuntz E, Gewillig M, Vlietinck R, Collen D, Carmeliet P 2005 Low expression VEGF haplotype increases the risk for Tetralogy of Fallot: a family based association study. J Med Genet 42:519-522

14. Vannay A, Vasarhelyi B, Kornyei M 2006 Single-nucleotide polymorphisms of VEGF gene are associated with risk of congenital valvuloseptal heart defects. Am Heart J 151:878-881

15. Xie J, Yi L, Xu ZF, Mo XM, Hu YL, Wang DJ, Ren HZ, Han B, Wang Y, Yang C, Zhao YL, Shi DQ, Jiang YZ, Shen L, Qiao D, Chen SL, Yu BJ 2007 VEGF C-634G polymorphism is associated with protection from isolated ventricular septal defect: case-control and TDT studies. Eur J Hum Genet 15:1246-1251

16. Verkleij-Hagoort AC, Verlinde M, Ursem NT, Lindemans J, Helbing WA, Ottenkamp J, Siebel FM, Gittenberger-de Groot AC, de Jonge R, Bartelings MM, Steegers EA, Steegers-Theunissen RP 2006 Maternal hyperhomocysteinaemia is a risk factor for congenital heart disease. BJOG 113:1412-1418

17. Hobbs CA, Cleves MA, Melnyk S, Zhao W, James SJ 2005 Congenital heart defects and abnormal maternal biomarkers of methionine and homocysteine metabolism. Am J Clin Nutr 81:147-153

18. Boot MJ, Steegers-Theunissen RP, Poelmann RE, van Iperen L, Gittenberger-de Groot AC 2004 Cardiac outflow tract malformations in chick embryos exposed to homocysteine. Cardiovasc Res 64:365-373

19. Botto LD, Mulinare J, Erickson JD 2003 Do multivitamin or folic acid supplements reduce the risk for congenital heart defects? Evidence and gaps. Am J Med Genet A 121:95-101

20. Lao O, van Duijn K, Kersbergen P, de Knijff P, Kayser M 2006 Proportioning whole-genome single-nucleotide-polymorphism diversity for the identification of geographic population structure and genetic ancestry. Am J Hum Genet 78:680-690

21. International Pediatric and Congenital Cardiac Code. Available at: http://www.ipccc. net/. Accessed July 25, 2009

22. Dudbridge F 2003 Pedigree disequilibrium tests for multilocus haplotypes. Genet Epidemiol 25:115-121

23. Barrett JC, Fry B, Maller J, Daly MJ 2005 Haploview: analysis and visualization of LD and haplotype maps. Bioinformatics 21:263-265

24. Horvath S, Xu X, Laird NM 2001 The family based association test method: Strategies for studying general genotype-phenotype associations. Eur J Hum Genet 9:301-306

25. Hu YQ, Zhou JY, Sun F, Fung WK 2007 The transmission disequilibrium test and imprinting effects test based on case-parent pairs. Genet Epidemiol 31:273-287

26. Shahbazi M, Fryer AA, Pravica V 2002 Vascular endothelial growth factor gene polymorphisms are associated with acute renal allograft rejection. J Am Soc Nephrol 13:260-264

27. Lambrechts D, Storkebaum E, Morimoto M, Del-Favero J, Desmet F, Marklund SL, Wyns S, Thijs V, Andersson J, van Marion I, Al-Chalabi A, Bornes S, Musson R, Hansen V, Beckman L, Adolfsson R, Pall HS, Prats H, Vermeire S, Rutgeerts P, Katayama S, Awata T, Leigh N, Lang-Lazdunski L, Dewerchin M, Shaw C, Moons L, Vlietinck R, Morrison KE, Robberecht W, Van Broeckhoven C, Collen D, Andersen PM, Carmeliet P 2003 VEGF is a modifier of amyotrophic lateral sclerosis in mice and humans and protects motoneurons against ischemic death. Nat Genet 34:383-394

28. Boot MJ, Steegers-Theunissen RP, Poelmann RE, van Iperen L, Lindemans J, Gittenberger-de Groot AC 2003 Folic acid and homocysteine affect neural crest and neuroepithelial cell outgrowth and differentiation in vitro. Dev Dyn 227:301-308

29. EACTS Congenital Database. Available at: http://www.eactscongenitaldb.org/db/ public-reports.py?fnc $=r 42 \&$ dbname $=$ database. Accessed on July 25, 2009

30. Ewens WJ, Spielman RS 1995 The transmission/disequilibrium test: history, subdivision, and admixture. Am J Hum Genet 57:455-464 